\title{
Some experience in an area health authority child health clinic
}

\author{
R S ILLINGWORTH
}

British Medical fournal, 1979, 1, 866-869

\section{Summary and conclusions}

Three years' experience as a doctor taking two clinics a week in an area health authority child health clinic was reviewed. A wide range of clinical conditions was seen, including: problems associated with feeding in breast- and bottle-fed infants; minor developmental abnormalities (mental, behavioural, and physical); surgical and orthopaedic conditions requiring treatment; medical conditions, mainly respiratory and alimentary infections, skin conditions, and problems of overtreatment for minor ailments; and minor genetic abnormalities. Mothers asked for advice on a wide range of topics, risks and benefits of immunisation being the most common.

The clinic doctor needs a wide experience in paediatrics to deal with such problems. It is suggested that all lecturers in child health and paediatric and senior registrars should take one clinic a week for six months, and all medical students should attend some clinics as part of their paediatric training. Health visitors have an important role in helping the clinic doctor, but their training should be more realistic and appropriate facilities should be provided to keep them up to date in their work.

\section{Introduction}

Three years' experience of area health authority child health clinics after many years of hospital work (which included a weekly baby clinic in the obstetrics hospital) provided me with some insight into the nature and value of such clinics. Because I think that many have little idea of the work done by the clinics I decided to try to outline the nature of the work seen by me in two clinics a week for three years. In every clinic I recorded the many problems, questions, and conditions with which I had to deal. All the conditions mentioned in this paper were seen by me personally, and no patients had previously been under hospital or specialist care for these conditions.

Children's Hospital, Sheffield S10 2TH

R S ILLINGWORTH, MD, FRCP, emeritus professor of child health, University of Sheffield

\section{Infant feeding}

The clinic doctor must be thoroughly conversant with infant feeding, whether by breast or by bottle, since he is constantly asked to advise about excessive wind (in bottle-fed babies this is usually due to too small a hole in the teat), inadequate weight gain (breast-fed babies), the age of weaning, the age at which cows' milk need no longer be boiled, breast milk being too "watery," etc. Much can be done to maintain lactation. A mother told me that her 6-week-old baby had been put on to the bottle a week previously because her milk "wasn't strong enough," and she was distressed because she had been given pills to stop lactation. Lactation was successfully re-established, with normal weight gain. A mother complained that her baby was yellow-he was, but he was not jaundiced: the mother, who was breast-feeding, had a predilection for carrots (I had previously seen a yellow baby on a weaning diet who was especially fond of carrots, which he had every day). If a baby is bottle-fed, one always asks how the feed is constituted-that is, the number of measures of powder and ounces of water per feed. Since the advent of the modified dried milks, mistakes such as overconcentration of the feeds are rare, but they are so important that the doctor should always inquire. Many mothers ask about the baby's stools, and the clinic doctor must know the normal variations, particularly the frequency (or infrequency) of stools in babies who are entirely breast-fed.

\section{Immunisation}

In every clinic I am asked about immunisation. Mothers are not alone in displaying considerable confusion about it. Much of the difficulty has arisen from ill-advised propaganda about ill-documented, supposed cases of brain damage after whooping-cough vaccine. I am disturbed to see children who have had whooping cough for several weeks as a result of the propaganda. I explain to the mothers that no antibiotic or other medicine alters the clinical course of whooping cough; that all immunisation procedures carry a small risk, which must be balanced against the risk of infection if no immunisation has been given; and that whooping cough can itself cause brain damage. I also mention the Scandinavian and American papers on the irrelevance of a history (and still less a mere family history) of fits, and the official recommendation of the American Academy of Pediatrics ${ }^{1}$ that unless progressive degenerative disease of the nervous system is present fits should not be a contraindication to DPT immunisation. If a fit seems to follow immediately after an injection, another injection would on no account be given. But in Britain, so long as the DHSS advises against it, it would be unwise to give a child pertussis immunisation if he has had fits in the past, for if further fits followed the injection would be blamed. A mother told me that six days after a DPT injection the child was drowsy and irritable for 48 hours, so I omitted the pertussis fraction in the next injection in case the symptoms were related to it, though this was unlikely.

Mothers have told me that their children have been refused pertussis vaccine for the following reasons: the child was a breech delivery, a twin, or a preterm baby; the child's uncle had eczema; the baby had eczema; the mother had had eczema in her first year; the husband had had a reaction to tetanus toxoid; the mother's father had had a fit at 1 year of age; her niece had had a fit; the mother had had a virus 
infection two years ago or, in another case, a mitral valve replacement. The workings of the human mind are sometimes indeed tortuous. The history of allergy in child or relative is irrelevant. A consultant said to me that he had been told that his whooping grandchildren were non-infectious because they had been immunised.

Many mothers who had refused pertussis vaccine and agreed to only DT polio for the first or second immunisation were worried by the whooping-cough epidemic, and asked whether they could change their minds. I therefore gave DPT polio and an injection of monovolent pertussis vaccine at monthly intervals (two doses). I am often asked whether the entire course of DPT polio immunisations should be restarted when there has been a long gap between injections ("because he always had a cold"); the answer is no. A baby from Canada had had three injections at 2, 4, and 6 months; I gave an additional booster at 18 months.

As for diphtheria and tetanus immunisation, a mother said that because she had had three fits she had been told that her son could not have DT vaccine. A mother asked me whether it was safe for her baby to have a DT injection because he had a running ear. On examination the discharge was wax. A boy of 3 had been given tetanus toxoid after a dog bite, though he had had no previous immunisation. A mother who had wanted her son to have the DT vaccine was asked whether she had ever had heart disease, and she asked me the relevance of the question. I did not know.

A mother was told that her child should not be immunised against poliomyelitis, because he was sensitive to eggs. That is irrelevant. But another child was refused because he was sensitive to penicillin. Theoretically, the refusal was reasonable because penicillin is used in its manufacture, but adverse effects in such a case have not been recorded. Though egg is used in the manufacture of measles, influenza, and yellow-fever vaccine, it is safe to give measles vaccine when the child is sensitive to egg. Two children had been refused measles vaccine because they had had eczema. I was asked whether it was safe to give measles vaccine to a child who had had a febrile convulsion with tonsillitis. I replied that the risks must be balanced, for fever is probably always present at the onset of measles, while only about $10 \%$ of children develop fever as a result of measles immunisation. A mother asked me whether it was safe to immunise her son when she was pregnant: the answer was yes. A mother asked me to immunise her child against measles. After the customary inquiry about whether the child was well, I gave the injection. As soon as she left my room she asked the health visitor whether it was all right for her son to have had the injection since he had just recovered from an attack of measles. I was asked whether a child who had had two attacks of anaphylactoid purpura could have TAB before a holiday in Tunisia. The answer was yes.

I have several times been asked whether the child should have his routine immunisation that day because he was a contact of a viral disease, such as, chickenpox or mumps. I have postponed the immunisation. I am repeatedly asked whether, while the child has a cold or is just starting one, it is safe to give the DPT polio or DT polio vaccine. I always postpone the immunisation, not because a cold predisposes to a serious reaction, but because if the child is beginning a serious illness, such as meningitis, the injection will be blamed for it. I always postpone poliomyelitis immunisation if the child has diarrhoea, because it might be ineffective. I have twice seen an Arthus-type reaction to DPT, and have avoided the pertussis fraction next time.

I could give many other examples of the questions that one has to answer, and the confusion that one sees. They illustrate the clinic doctor's need to be thoroughly knowledgeable about immunisation.

\section{Development (including physical variations)}

The clinic doctor must be well experienced in mental, behavioural, and physical development. A rough assessment of development is part of the routine examination of any baby or young child, and every clinic doctor needs to know the essential features to look for, ${ }^{2}$ cutting out all irrelevancies. I am often impressed by the mothers' gratitude when I tell them that their children are developing normally. But normal variations-such as backwardness in sitting, walking, talking, or sphincter control-are often seen and the clinic doctor must know the reason for them. He must also recognise the abnormal, or at least know when to seek advice from an expert. He must be conversant with the normal variations in muscle tone in early infancy, and know what signs suggest the possibility of cerebral palsy, ${ }^{3}$ though he will see few cases because the incidence has declined. I have seen two cases of cerebral palsy in the three years, two suspected cases (though the children were normal), and one with an extreme variation of muscle tone-spontaneous leg clonus-that I knew would probably disappear in a few weeks. One of the children with cerebral palsy was a 4-year-old, whose mother told me that he often "cottles over" (meaning falls); he had a mild hemiplegia.

Observing the relationship between mother and child and discussing it with the health visitor, who knows the family, helps the clinic doctor not only to treat simple behavioural problems but to prevent them from developing. He must be thoroughly conversant with normal behavioural development and the normal variations. He will constantly need this knowledge to guide mothers about problems of sleeping, eating, toilet training, negativism (notably in children aged 1-3 years), thumb sucking, tics, soiling, head banging, breath-holding attacks, frequency of micturition as an attention-seeking device, and crying. ${ }^{4}$ I have dealt with these problems many times in the clinics. Perhaps the most important are the problems of sleep or constant crying, which may be so serious that they threaten the marriage or predispose to child abuse. One has to deal with all these without giving medicine. I am impressed by the gratitude expressed by mothers who had been at their wits' end over a baby's refusal to sleep, when in a week or 10 days my advice has been taken and the problem has been solved. I have also had to advise about an occasional delinquent and about stuttering, which is not strictly a behavioural problem. A mother asked for advice about her $4 \frac{1}{2}$-year-old's constipation: she always sat on the lavatory seat herself when he was on the pottie, so that he would imitate her. He did not.

An important contribution that a clinic doctor should and can make is to advise parents on how to bring out the best in a child-for instance by reading to him and giving him suitable play material.

The clinic doctor constantly needs paediatric knowledge and experience of normal physical development, normal variations, and the reasons for these variations, and he must be able to recognise the abnormal. Apart from unduly small children (who usually take after one of the parents or were low birth-weight babies) or overweight children or those who are just beginning to gain weight excessively, other problems include: a big head (commonly like that of a parent); umbilical hernia; incompletely opened nasolachrymal duct; divarication of the rectum; early or late closure of the anterior fontanelle; asymmetrical skull in infancy; epicanthic folds; single palmar crease (commonly normal); asymmetrical gluteal or thigh creases (commonly normal); late teething; facial milia; breast enlargement in the young baby; habit toe-walking (to be distinguished from organic causes of toe-walking, such as cerebral palsy or congenital shortening of the tendo Achillis); and a long or not easily retractable foreskin. I have seen all these conditions in the clinics. None requires treatment (except, rarely, the incompletely opened tear duct). One 18-month-old child, with no features of familial dysautonomia, had never shed tears. I am often impressed by some doctor's conscientious recording of the description of the foreskin, as if it matters-though occasionally a hooded prepuce may need cosmetic treatment. Functional cardiac murmurs are common and $I$ mention it to the mother only if the murmur is obvious, in case someone else worries her about it later.

Semi-surgical conditions that I have seen in the clinics, which do not require treatment (or a surgical opinion), have included cysts on the scalp, tongue, gum, or breast; hydroceles (several); a thorn in the hand; hymen tags; lipoma in the sole of the foot; congenital torticollis (several); frontoparietal osteoma; congenital dermal sinus (several); alveolar frenum (which rarely needs treatment); tongue-tie (several); turning in the foot (many); and knock-knee or bow legs (many).

\section{Surgical and orthopaedic conditions}

Surgical conditions that required treatment included: inguinal hernia; undescended testes; preauricular sinus; umbilical polyps; congenital pyloric stenosis; accessory digits or auricles; hydrocephalus; meibomian cyst; donkey ears; and an imperforate hymen. Several infants with presumed benign congenital laryngeal stridor were referred to hospital for laryngoscopic confirmation of the diagnosis. Children with suspected squint were referred to the hospital eye clinic. Though I know exactly how to tell others how to diagnose a mild squint, I often find it difficult when faced with an individual baby.

Orthopaedic conditions consisted mainly of many doubtful hips; an amelia (the only possibly relevant cause being diazepam in pregnancy); talipes; trigger thumb; and a Sprengel's deformity. Examining the hip is part of the routine examination of babies, but about one in 25 of those seen at 6 weeks have some limitation of 
abduction, usually on the left; they are mostly girls. I refer these to the orthopaedic surgeon. Unfortunately, opinions differ about the importance of an $x$-ray examination and about management of doubtful cases. I see many babies who are said to have had a "click" in the hip, though this is now regarded as being of little or no importance. Several had had "double nappies" applied, though they are useless.

\section{Medical conditions}

I see many infections, mainly respiratory and alimentary; and often the mother asks for a second opinion after her family doctor has seen the child. I can never refuse, because so much can be done to relieve her anxiety. I am always impressed by the faith that mothers show in the baby clinic. Infections seen included: severe whooping cough in a child aged 6 weeks, who was sent into hospital immediately urinary tract infection (diagnosed by dipslide in the clinic); chickenpox in a child aged 7 weeks; mumps; roseola infantum; bronchopneumonia; chronic salmonella infection; conjunctivitis, not responding to treatment; purulent nasal discharge; nits; recurrent sore throat; and otitis media. Oral moniliasis is often seen in young babies. A child was brought to me because he had been ataxic for 48 hours, though he had begun to improve; he had herpes on a toe. When I was seeing a schoolboy, the mother said "By the way, will you see our Mary ?" (aged 15). I did and, to my surprise, found an acute mastoiditis with a polyp protruding from the discharging ear. She was admitted to hospital that day for operation.

I see many skin conditions, including scores of nappy rashes, spotty faces, and scurfy scalps, with occasional impetigo, herpes, eczema, soreness behind the ear, "sticky umbilicus," ichthyosis, sensitivity to the elastic on pants, seborrhoeic dermatitis, and several naevi of various kinds. There were two cases of congenital defect of the scalp, one case of molluscum contagiosum, one of pityriasis alba, and one of naevoxanthoendothelioma. Above all, the clinic doctor must be conversant with nappy rashes-in my experience the monilial nappy rash, especially if secondary to ammonia dermatitis, is almost universally missed. Commonly, but not always, oral thrush is also present. I saw only one or two cases of the psoriasiform and seborrhoeic varieties.

Other medical conditions included: a baby with hypercalcaemia; a Russell-Silver dwarf (previously termed "failure to thrive"); a case of Duchenne muscular dystrophy; congenital ptosis; an infant with sinus tachycardia (which resolved spontaneously); and three children with a ventricular septal defect. Several children had asthma, ruttling, and migraine or the periodic syndrome; and others had recurrent abdominal pain or the "irritable colon" syndrome of the toddler (diarrhoea with no other symptoms and normal weight gain). Several children had convulsions, in some cases due to breath holding and not requiring treatment, but some had epilepsy (including one baby seen during a convulsion). A schoolboy was seen because he was doing badly at school and speaking indistinctly; he looked gormless, with open mouth. To my surprise, on developmental testing I found that his IQ was around 110 and that he was deaf.

Social problems such as prebattering or child abuse and infants who are constantly crying are more troublesome, but the health visitor in the clinic, who knows the family, is always there to help. One such baby, the son of professional parents, was of special interest. I could find no error of feeding or of withholding of love. I suggested a trial of soya-bean milk, with immediate "cure"; a provocation feed of a cows' milk preparation caused crying for 24 hours. I then arranged a "blind" experiment, with the father feeding the baby for several feeds, interposing a feed of a cows' milk preparation without the mother's knowing, and 24 hours' crying resulted. I see a few infants with evening colic, and they respond to dicyclomine hydrochloride (prescribed by the family doctor) if the symptoms satisfy the criteria for the diagnosis, ${ }^{4}$ but more babies have symptoms that do not satisfy the criteria. They have "colic" during the day, and are given dicyclomine as a "panacea" for crying, without effect. One such child, whose crying stopped as soon as he was picked up and loved, had been treated unsuccessfully with an antihistamine drugan unusual treatment for wanting love.

Overtreatment is common. It seems that every child who is taken to a doctor for a cold is given penicillin, and most are given nose drops, which in my opinion are unnecessary and may themselves cause rhinitis. Harmless "snuffles" are also treated by nose drops. I have seen tetracycline-stained teeth, because the doctor had not realised that tetracycline is absolutely contraindicated under the age of $\mathbf{7}$ or $\mathbf{8}$ years. I gather that every exacerbation of asthma is treated by penicillin, though the infection leading to the exacerbation is usually viral; and the normal posseting of the young baby is treated by metoclopramide or prochlorperazine. In the clinics one soon learns about the efficiency or otherwise of hospital doctors in replying to letters about children referred to them, and about the adequacy and thoroughness of follow-up.

\section{Genetic factors}

Doctors in child health clinics see interesting, but usually unimportant, genetic conditions that are unlikely to be seen in hospital. Over the three years those that I saw included: preauricular sinus in child and mother; hypospadias in boy and father; tongue-tie in child, mother, and grandmother; accessory nipple in child, mother, and grandmother; congenital nystagmus in baby, mother, maternal grandmother, maternal sister, and the latter's daughter; incurving little finger in baby, mother, mother's two brothers, and grandmother; atrophic finger nails in child and father (no relevant drugs in pregnancy); late teething in child and two siblings; two deaf siblings, one of whom had koilonychia and the other onychogryphosis (chromosomes later shown to be normal); and pyloric stenosis in child and mother, and in another case in child, father, and two uncles.

\section{Questions and comments}

Questions asked by mothers cover a wide range of topics. I have been asked for advice about precautions to take when travelling with children in Bulgaria, the Canary Isles, Majorca, and Tunisia; the danger of nitrates in water in the country; whether a 6-month-old baby could be tried in the swimming baths; whether an 8-month-old baby could take coffee, as he refused all other liquids; how long hiccoughs after feeds and jaw-trembling last in babies; what to do when the shoes will not stay on, and when the child refuses to wear boots; what to do about the baby handling the penis; the genetics of schizophrenia (two cases); and whether mongolism and alopecia are connected (the answer was yes). One mother said, "When I got caught with Mary, I was having electrical treatment. Would it do any harm ?" One mother, who weighed only $50 \mathrm{~kg}$ and was $1.5 \mathrm{~m}$ tall, was worried because her daughter was very small (below the 3 rd centile). When I asked her whether it would be surprising if the girl took after her, she said "Yes, it would, she's adopted." A woman said that her boy's urine was "beautiful-just as clear as tap water." A mother said that her baby was "always positive" (posseting). When a baby whom I was examining passed a stool, his 3-year-old brother said "He's done shit." His mother said "That's very rude; say he's done a pooh-pooh." A 2-year-old had eczema-the mother had been told in a hospital "To watch out for the development of asthma."

\section{Discussion}

My outline of the clinical conditions and problems seen in two local authority clinics a week for three years gives some idea of the role of the paediatrics-trained doctor in health education and preservation of health, and prevention, early diagnosis, and treatment of disease. The clinic doctor is in an ideal position to allay parents' worries about physical growth, behaviour, and mental development, and guide them in their desire to help their child to achieve his best. To some extent he fills the gap between the family doctor, who is too busy and has a long waiting list, especially during an epidemic of infectious disease, and the hospital specialist. His position is similar to that of the paediatrician who is head of a paediatric accident and emergency department, for he can never refuse to help a mother or give another opinion if asked. He knows that what is trivial to a doctor is important for the mother, and he is privileged to be able to allay her anxieties. Many of the problems for which she seeks help are the province of her family doctor, but an anxious mother cannot be blamed for wanting a second opinion. The doctor is greatly helped by the health visitor, not only because she knows the family, but because she can visit the home between clinic visits, and so is able to complement his advice to the mother about feeding and behavioural or minor medical matters and help her to carry it out. 
The clinic doctor needs all the clinical judgment and experience that he can muster. Unlike the doctor in a hospital outpatient clinic, he does not have access to facilities for investigation and second opinions from colleagues. In the clinics I often have to decide whether to ask for investigation or merely to see the child again. Such cases include: children with an unusually small weight or height with no obvious cause; glands in the neck; excessive posseting; recurrent abdominal pain; backwardness in development; patches of hypopigmentation; bruises other than those on the legs; a black eye or a subconjunctival haemorrhage with a dubious explanation; a liver edge at the upper end of normal; or vague lassitude. Three times I had to decide whether to investigate a well child with a palpable spleen (I had a blood count done in one only, and observed the others). I sent a child with prolonged physiological jaundice for thyroid function tests.

In a single clinic I had to deal with babies with a palpable spleen, reduced abduction of a hip, a patch of hypopigmentation, and oral monilia; an ill-nourished breast-fed baby who was perfectly content to starve; a child who had had a convulsion; and a case of possible child abuse. In another clinic I dealt with two overweight babies, an underweight baby, whooping cough, a cardiac murmur, photosensitivity (not related to drugs), a doubtful hip, epiphora, and an umbilical polyp. On both occasions I had also to deal with mundane questions and immunisations. When faced with immigrant families who cannot speak a word of English, and a child is underweight or the mother seems to be worried about something, I try to imagine how we, as lay people in their country, would feel if our children had worrying symptoms and we could not speak a word of their language.

Drugs are not used in the clinics, so clinical judgment must be used and the family doctor's help sought if treatment is indicated and hospital investigation is not required. The family doctor must always be kept informed, and consulted when he can help. I firmly believe that all lecturers in paediatrics (and perhaps paediatric registrars and senior registrars) should have to conduct one child health clinic a week for six months as part of their training. Apart from anything else, it would be invaluable experience for them to have to treat without giving medicine as a substitute for counselling.

Nevertheless, it would help many mothers if the clinics were to provide treatment for a strictly limited number of common conditions-namely, oral monilial infection, nappy rashes (only ammonia dermatitis and monilial infection, single or combined), and perhaps a spotty face and evening colic. I have often wished that haemoglobin measurements could be done in the clinic. Since they cannot, the doctor has to guess and may make a mistake. The clinic doctor should also be able to supply ferrous sulphate. It is unfair to a mother, particularly if she has other small children, to have to go from a child health clinic to a doctor's surgery just to obtain nystatin drops. In my two clinics we are supplied with dipslides so that we can send a specimen to the hospital for urine culture; again, it would be unfair if a mother had to take her child 10 or 20 miles to a hospital to have a urine specimen cultured. The clinic doctor is often asked for a second (or first) opiricin on a child's lassitude or other vague symptoms, and his opinion is worth more if he is able to eliminate a urinary tract infection. It alsu helps the family doctor to know that the infection has been eliminated.

To give the best advice, clinic doctors need to keep up to date, and facilities such as lectures by experts and seminars on practical day-to-day subjects should be provided. Lectures and discussions that are relevant to the daily work of health visitors should also be available, rather than courses on business management or NHS finances. I suspect that courses for training health visitors may be becoming too theoretical and high falutin-I have seen health visitors' examination papers from various parts of Britain and fear that on many of the questions I would score nothing. A well-trained clinic doctor can help health visitors considerably in answering their questions, seeing and discussing cases referred to him, and showing them cases that may be important to their work.

The clinics are invaluable for health education. I believe that they could do much more by having free booklets, written by experts (not drug firms or dried-milk manufacturers), on practical subjects such as breast-feeding, bottle-feeding, common behaviour problems, choice of play material, immunisation, and helping the child to achieve his best.

I thank Dr Marion Jepson, specialist in community medicine (child health), Sheffield, and $\mathrm{Dr} \mathrm{T} S \mathrm{~S}$ Adams, specialist in community medicine (child health), Rotherham, for reading this paper and for their helpful comments.

\section{References}

1 American Academy of Pediatrics, Committee on Infectious Diseases, Report. Evanston, Illinois, 1977.

2 Illingworth, R S, Basic Developmental Screening, 2nd edn. Oxford, Blackwell Scientific, 1977.

${ }^{3}$ Illingworth, R S, The Development of the Infant and Young Child, Normal and Abnormal, 7th edn. Edinburgh, Churchill Livingstone, 1979.

4 Illingworth, R S, The Normal Child, 7th edn. Edinbureh, Churchill Livingstone, 1979.

(Accepted 15 Fanuary 1979)
A 48-year-old patient who suffers from contact dermatitis-possibly an allergy to a washing liquid-finds that his dermatitis gets worse after drinking beer and almost clears when he stops beer drinking. Is the disappearance a coincidence?

I would want very strong evidence before accepting this as a causeand-effect story. How many times has stopping the beer drinking led to clearance of the dermatitis within, say, a week or two, and without other treatment? And how many times has a clear-cut relapse occurred within, say three to four days of returning to the habit? Acquired eczema such as this is one of the least common manifestations of ingested allergens and my sceptical attitude is born of numerous experiences of similar allegations shown to be entirely mythical when deliberately and repeatedly challenged by an objective observer (not the patient). If cause and effect can be proved clearly and repeatedly, explanations could be very interesting-for instance, allergy to Candida albicans or yeast, or both, allergy to metals such as nickel, cobalt, or chromates, or even to Bacillus subtilis enzymes if washing powders are involved. Clearly, further investigation is warranted if the basic clinical facts can be confirmed. One final point-contact dermatitis from a washing liquid is more likely to be due to a primary irritant chemical or degreasing dermatitis than to be based on a true allergic mechanism.

Is there any danger in sleeping in a bedroom that is very close $(4 \mathrm{~m})$ to a sodium street lamp? It is on for about 15 hours in 24.

The obvious potential hazard arises from the emission of ultraviolet radiation but as it falls off in inverse proportion to the square of the distance from the source, even $4 \mathrm{~m}$ is a comforting distance away. Moreover, sodium street lamps are encased in high temperature glass that is usually leaded, with an outer envelope and often a vacuum in between. Very little ultraviolet radiation is likely to escape, and there is no published evidence to suggest that any actual hazard arises. Theoretically, the monochromatic sodium rays could affect the eye, but, likewise, there is no evidence that they do. Physical barriers to the light will obviously provide reassurance and, especially if the window is normally kept open, venetian blinds or curtains could provide varying degrees of screening, if only to avoid distraction to the occupant. 